\title{
INTERNATIONAL OPHTHALMOLOGICAL CONGRESS, 1929
}

\section{Subscribers to International Ophthalmological Council Fund}

\author{
THIRD LIST
}

Societies, Institutions, etc.

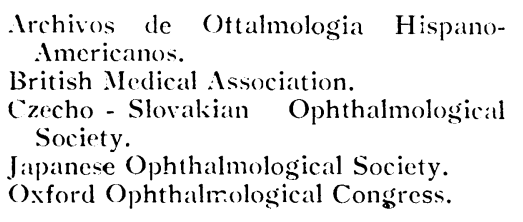
Royal Westminster Ophthalmic Hosp:tal.
Section on Ophthalmology, Collegie of Physicians of Philadelphia.
Ophthalmological Society of Egypt. .
Ophthalmological Society of Valparaiso.
Ophthalmological Society of IVarsaw.

1 group of Cicrman ophthalmologists, by farour of Geh. Hofrat Professor I)r. Th. Axenfeld.

Ask, Fritz.

('haillous, J.

Cirincione, Giuseppe.

Cirincione, Speciale.

Cozzoli, Giulio.

I)alén, Albin.

Fileti, Antonio.

Finnoff, Wm. C.

Gomès, Percira.

\section{INDIVIDU.ILS.}

Ishihara, Shinobu.

lo Cascio, Girolamo.

Luppino, Andrea.

Magsiore, Luigi.

Marsotta, Giuseppe.

Oguchi, Chuta.

Orio, Giuseppe.

Picciche, Speciale.

Radcliffe, McCluney.
Roselli, Remeo.

Sartain, Paul J.

Snell, H. C.

Terrien, F.

Velez, Danicl M.

Wardale, J. D.

Zappalà, Antonino.

\section{ABSTRACTS}

\section{I.-REPORT OF COMMITTEE ON OPTICIANS' (REGISTRATION) BILL}

\section{* Report of the Committee appointed by the Minister of Health and the Secretary of State for Scotland on the Optical Practitioners' (Registration) Bill, I927.}

The Committee appointed last year to consider the Optical Practitioners' (Registration) Bill (Brit. Jl. of Ophthal., Vol. XI, p. 235, 192 ) has issued its report consisting of a majority report, signed by nine members including the chairman, and two minority reports, signed by three members and one member respectively,

\footnotetext{
${ }^{*}$ Pp. 27. H.M. Stationery Office, London, 1927. Price 6d.
} 
the latter, Mr. Rhys J. Davies, being abroad when the report was drafted.

The proceedings were conducted in private, no reports being made to the Press. An appendix gives the names of the bodies and persons who submitted statements of evidence to the Committee. This evidence was considered to be too voluminous to be printed, but, judging from the list, the side of the optician was adequately represented, as well as that of the approved societies.

The Committee state that they did not consider themselves restricted to a consideration of the registration of opticians under the provisions of the present Bill, but thought it advisable to examine in a comprehensive manner the problems which the subject appeared to them to raise. Thus, Part I of the report deals with the consideration which these problems have already received in this country; to the chief factors which have contributed in recent years to the necessity for an inquiry; to the provisions for registration in other countries; and to the nature and promotion of the Bill under consideration. Although a "Sight Testing Opticians' Bill" was introduced into the House of Lords as far back as 1906 , the subject was first seriously discussed by the Departmental Committee on the Causes and Prevention of Blindness and the Royal Commission on National Insurance which reported in 1922 and 1926 respectively (vide Brit. Jl. of Ophthal., Vols. VII and XI, pp. 5i and 93, 1923; and pp. 2i, 235, 288, 192i). The report at present under notice recapitulates the nature of the evidence on which the Departmental Committee decided against the claim to registration and also the considerations which led the Royal Commission to point out that similar difficulties were beingencountered to those met with when the State found it necessary to limit the practice of dentistry and midwifery to those possessing the necessary professional qualifications. Further, that the difficulties became greater as the volume of unqualified practice increased, and suggested that, if it became necessary to regulate the practice of opticians, much was to be gained by taking the necessary step while the problem was still manageable. The arrangements for Ophthalmic Benefit under the Insurance Act are next set out; with these our readers should be fairly well acquainted. A paragraph follows commenting on the confusion caused by the variety of titles used by opticians, the marked variations in the standards required by the various optical organizations, and the comparative worthlessness of some of their diplomas. The question of the effect of the sale of cheap spectacles is not considered worthy of further inquiry in view of the opinion held by the Committee as to the nature of any register which could be established in this country. Provision is made by law for the registration of opticians in parts of Canada, 
Australia, in most of the United States of America, and in Jamaica. The Committee state: "From the evidence which we have received it seems to be agreed that this legislation has been effective in putting down the unregulated sale of spectacles, and has had the effect of raising the standard of qualification of opticians, and from this point of view we may conclude that the Acts have had a beneficial effect. We have not, however, been able to obtain any very clear evidence as to whether this legislation has resulted in an increased reference to medical practitioners of cases of defective sight which require treatment by medical means rather than by the provision of glasses. In any event we are not satisfied that the conditions are comparable." Part I concludes with the following statement as to the nature of the present Bill. "The Bill is not prohibitive in the sense that it would exclude unregistered opticians from continuing to practise, as is the case in most of the other countries to which our attention has been called. It proposes to leave to a board the duty of deciding the qualifications which would entitle an optician to be placed on the register, and, theoretically at least, it would be possible for a great number of existing opticians to be refused admission to any register which might be set up under the Bill."

Part II of the Report is subdivided into three sections. Section I deals with the relationship between the public on the one hand and oculists and opticians on the other, and the kind of register which could be set up; Section II with the limitations which would have to be placed on the practice of such registered opticians; and Section III with the final conclusions on the main issue.

The subject matter of Section I is apt to be somewhat neglected and the importance attached to it throughout the Report is a very satisfactory feature. It is stated that in the best interests of the patient the examination of his eyes should, if possible, be carried out by an oculist. This is unfortunately only possible in the case of hospital patients, elementary school children, and private patients who can afford to pay the necessary fees. The approved societies are unable to find a fee of one guinea for every insured person who complains of defective sight and it is, therefore, obvious that for a large section of the community the optician may be said to be recognized as the natural person to be consulted in cases of eye trouble, while the oculist is regarded as a luxury. Further, the Committee state that they have every reason to believe that of that section of the community who have their sight attended to privately, large numbers adopt the same attitude. It is only natural, therefore, that there should arise a demand that a register should be set up whereby both approved societies and individual members of the public may be enabled to differentiate between one class of optician and another, and be safeguarded from imposition. 
The point at issue is whether the manifest advantage to the public of producing some sort of order out of the present chaos outweighs the disadvantage of affording State recognition to what, at best, can oniy be a partial service.

The next point deals with the problem of admission to any such register, a register which the Committee wisely judge could not be made prohibitive. "For example should aspirants for admission be compelled to satisfy the Board either individually or with reference to a diploma already granted, that they have the capacity not necessarily to diagnose but to detect the existence of any condition of the eve which would render the prescription of glasses at best a mere palliative, and at the worst a positive danger." In this connection the Committee, while not prepared to lay too much stress on percentages, are of the opinion that the number of cases in which an apparently simple error of refraction is complicated by other ocular disease is greater than has been supposed to be the case. The Committee feel obliged to say that they are not satisfied that there is any training for opticians sufficiently thorough to avoid the danger which is involved in a little medical learning. The Joint Council of Qualified Opticians, which is regarded as representing the highest standard at present obtained, draws its members from two other bodies, the British Optical Association, and the Spectacle Makers Company. Of these two, the former examine their candidates in the detection of disease while the latter do not. Further, the possible effect of any register on the business of the pure dispensing opticians requires serious consideration. At the least, in their defence, a supplementary register of dispensing opticians would be essential.

Section II deals with the necessary limitations on the practice of registered opticians. In the first place the use of drugs would have to be prohibited, a restriction which would render the recognition of intra-ocular disease almost impossible in cases with very small pupils. Even an experienced ophthalmologist would hesitate in giving an opinion on the state of the macula without, in the majority of cases, dilating the pupil. Further, as regards treatment other than that by glasses the Committee hold the opinion that this should be absolutely prohibited, as also the use of any title which would confuse or mislead the public as to the function of the registered persons. Finally, as regards advertisement it is generally recognized that the establishment of a register on a professional basis inrolves abstention from advertising. The use of advertisement, however, would be still open to the unregistered practitioner.

The final section gives a summary of the conclusions reached and is here reproduced in full, since any further abbreviation is hardly practicable. 
"40. At this point we think it advisable to sum up the conclusions which we have reached in the two preceding sections. We have seen that the functions of even the best qualified opticians should be restricted to the use of mechanical means for the correction of errors of vision, and that in the best interests of the patient the responsibility for any examination of the eyes should be upon an oculist, who, in addition to having access to all the resources of the skilyed optician, can bring to bear the whole of his medical experience either in deciding that it is possible to determine the absence of disease or, on the other hand, to recognize and to treat any diseased condition that may be present. Opticians cannot, therefore, provide more than at best a partial service, but in view of the fact that large sections of the community in present circumstances do not avail themselves of the services of oculists and of the fact that the public are not in a position to recognize which are the most competent opticians, there is a prima facie case for setting up a State register in order to produce some sort of order out of the present chaos.

41. As, however, a considerable proportion of cases of defective vision are not cases of mere refractive error but require treatment other than, or in addition to, the provision of spectacles, it follows. that the very prescription of spectacles involves an implied decision that no other treatment is required; and we think that this consideration must necessarily govern the standard to be set for admission to any register. After a careful review of the facts regarding the training of opticians as a whole, we have been forced to the conclusion that it would not be in the public interest to set up a prohibitive register which would involve the admission of practically all opticians who were able to show that they have been conducting bona fide businesses. At the same time the setting up of a non-prohibitive register would be useless if not dangerous unless it were made a condition of entry that every candidate should prove to the satisfaction of the Board his ability to exclude the possibility of the existence of disease before prescribing spectacles. We are not satisfied that even those opticians who are most highly qualified in all other respects are sufficiently trained in this respect.

42. Further, the setting up of a register of sight-testing opticians would necessitate the separate registration of opticians who undertake dispensing only.

43. In Section II we find that it would be necessary not only to impose restrictions on registered opticians in the way of treatment, of advertising, and of using confusing or misleading titles, but that it is imperative that they should be prohibited from using drugs. Such a restriction would in effert severely limit the classes of patients whom the opticians would be capable of treating. 


\section{Final conclusions}

44. In view of all these conclusions we are convinced that the setting up of a State register of sight-testing opticians is not in itself a desirable policy. There remains, however, the question whether it is nevertheless necessary, having regard to existing circumstances, to adopt this expedient in the public interest. In our opinion the answer to this question depends on how far the medical profession is likely to be able to make the services of oculists available for persons in those sections of the community for whom at present they are, for economic reasons, not available.

\section{Prospect of the extension of the services of cculists}

45. Whether it is as the result of the establishment by approved societies of ophthalmic benefit, or of the question of registration becoming acute, or of the increasing competition of better trained opticians, or merely of the greater public recognition of the importance of defects of vision, we are satisfied that there exists a movement on the part of the medical profession to provide treatment by oculists on terms which will make that treatment much more readily accessible to the public. Whe are assured, for example, that so far as insured persons are concerned, negotiations are at present being conducted by the British Medical Association with a view to the establishment in all the more populous districts of clinics or other schemes by which the services of oculists would be made available at fees within the reach of approved societies, having regard to the limited funds available for ophthalmic benefit.

\section{Number of oculists available}

46. Moreover, we are satisfied that in recent years an increasing number of medical men, and particularly the younger men, have been making a special study of ophthalmology; also, that there is good reason to believe that a supply of oculists, sufficiently well distributed to meet reasonable demands, will be forthcoming. The setting up of a State register of opticians would not encourage and might indeed retard these movements. We feel that it would ine a retrograde step on the part of the State to do anything to discourage the provision of the best form of treatment for the greatest possible number of patients.

\section{Future of opticians}

4\%. It has been claimed, probably with truth, that the setting up of a State register would incite those responsible for the training of opticians to raise the standard of qualifications, but we see no reason why the improvement in methods of training 
which.. has been made in the last 10 or 15 years should not be maintained, though no register is set up. Whether the register is set up or not we feel sure that numbers of the population will resort to opticians in the future, as they have done in the past, and we think that the natural competition which will be engendered by the movement on the part of the medical profession to which we have referred will have the effect of raising the standard in both classes of practice. Further, in view of the large numbers of opticians who are undoubtedly capable refractionists, we consider it would be beneficial in the public interest if use could be made of their services in that capacity in collaboration with and under the control of oculists, and we commend this view for consideration in connection with the negotiations referred to in paragraph 45.

48. While we have been forced to conclude that it is not in the public interest that a State register of opticians should be set up, we desire to emphasize that one of the principal reasons on which we base this opinion is our view that it is possible and probable that the medical profession will be able to provide insured persons entitled to ophthalmic benefit with the services of oculists at an early date, and at fees within the limit of the funds from time to time available to approved societies for this purpose. We hope, also, that such a service will be extended to the non-insured population. If, however, for any reason, these hopes are not fulfilled within a reasonable time we do not wish our Report to preclude the possibility of a reconsideration of the question in the light of the circumstances then existing."

The two minority reports, the first signed by Messrs. Aves, Barker and Houghton, and the second by Mr. Rhys J. Davies are both in favour of a registration Bill on the proposed lines. The first states that "We consider it, therefore, unreasonable for the Majority Report to conclude that a State register is almost inevitable and then to ride off from this conclusion on the strength of an unexplored promise from one of the interested parties (traditionally jealous of subsidiary professions bordering upon their own) a promise that, even if taken at its face value, does not hold out any prospect which in the light of the accumulated evidence before us can be regarded as giving substantial relief to the serious needs of the situation. . . . We conclude, therefore, that the case for the regulation of the practice of optometry by means of a State register is well supported, and that the Committee incurs a serious responsibility in making an indeterminate report. . . A A non possumus attitude now that the issue has been thus prominently raised will certainly give countenance to the idea that there is no intention whatever to interfere with undisciplined practice, and this in itself would be little short of a public disaster." 
Mr. Rhys J. Davies', in the second Minority Report, while in agreement with many of the statements in the Majority Report, draws attention to the usual effect of registration in other professions in increasing fees and costs in general to the customer, and recommends that definite precautions should be taken to prevent the imposition of exorbitant charges for sighttesting and appliances. He considers that there should be at least two representatives of the approved societies on the Registration Board to represent the interest of the consumers. He concludes by saying that: "the register on its first compilation should include, in addition to those of undoubted qualification and training, a limited number of those with a wide experience of sight-testing and the sale of appliances, but who are now without other qualifications. There should, however, be a time limit to the operation of this principle; and, say as from January 1,1930 , a universal standard should be set before further names are added to the register."

E.E.H.

\section{II.-OPTICS AND REFRACTION}

(I) Bretagne, M. P. (Nancy). - Micrometric ophthalmoscopeo lens. (Loupe ophtalmoscopique micrométrique.) Ann.? d'Oiul., CLXIII, p. 192, 1926.

(1) Bretagne, as a result of the frequent employment of the graduated ocular in a corneal microscope, was moved to devise the following method for measurement of changes observed in ophthalmoscopy. A scale in millimetres for an extent of three centimetres is engraved on the lens used in indirect ophthalmoscopy. This scale is placed somewhat eccentrically so as to allow of a clear view of the fundus in ordinary examination and also to allow of measurement of any part of the area of fundus in view by simple rotation of the lens. Bretagne emphasizes the fact that by this method actual measurement is not obtained, but records can be taken which are of value in particular cases. The size of an image visible in the fundus oculi varies with : (1) the focal length of the ophthalmoscope lens; (2) the refraction of the observed eye; (3) the distance of the lens from the nodal point of the eye (in ametropes); (4) the distance of the lens from the observer.

In general a lens of 13 dioptres is used; the distance of this lens is usually its focal length ( 77 millimetres for 13 dioptres); that is the position which gives the largest field of view. The distance at which the observer holds the lens from his eye depends upon his habit and his anatomical structure. Although the image 
of the fundus and the scale engraved on the lens are not in the same plane, it is claimed that they appear to be in focus at the same time.

\section{Humphrey NeAme.}

(2) Dupuy-Dutemps, L. (Paris).-Modifications of the sensation of relief (or prominence) produced by decentred spectacle lenses and by prisms in binocular vision. (Les modifications de la sensation de relief produites par les verres de lunettes décentrés et par les prismes dans la vision binoculaire.) Ann. d'Ocul., Vol. CLXIII, p. 673, 1926.

(2) Dupuy-Dutemps describes and explains a fact which is little known with reference to stereoscopic vision. The fact is one of considerable importance, in that one who is conversant with it is able to translate certain symptoms of which a patient may complain in the use of spectacles. The fact is that on looking through two prisms placed base inwards at a vertical rod (or line), an observer sees the rod apparently curved with its convexity towards him. In the case of a plane surface he sees this surface apparently domed. If the prisms be reversed and placed with their bases outwards, such a surface will appear to be hollow. A similar phenomenon is observed if convex lenses are placed in front of the eyes and displaced inwards or outwards respectively, owing to the prismatic effect of decentration. The truth of this is very easily tested by using two prisms of four dioptres and looking at a plane surface near at hand, provided that the observer possesses good stereoscopic vision. An opposite result is of course produced with concave lenses. The reason for this stereoscopic anomaly is that a prism, base to the left, in front of an eye, makes vertical lines appear concave to the right, and a prism in the reverse direction makes such lines appear concave to the left. The fusion of the two images in stereoscopic vision gives the appearance of prominence or relief. Cylinders with axes vertical behave in a similar manner. The sensation of distortion is increased with lenses of higher power and with greater degrees of decentration. It is sometimes a cause of discomfort in patients when for the first time they use spectacles with decentred lenses or with prisms for defective convergence. Some can never accustom themselves to the new conditions. The knowledge of these facts enables a diagnosis to be made as to errors of centration of lenses and the correction required.

- Humphrey Neame.

(3) Sedan, J.-A note on inflammatory myopia. (Note sur le myopie inflammatoire.) Ann. d'Ocul., CLXIII, p. 358, 1926.

(3) Sedan reports two cases, a man, aged 25 years, and a boy, aged 13 years, in whom transient myopia developed as a result of 
acute iritis. In the former the cause was secondary syphilis, in the latter a severe attack of fever of fifteen days' duration with gastro-intestinal symptoms which preceded the iritis and subsided four days previously to its onset. In each case there had been previous examination by an oculist. In the man the affected eye had been emmetropic with vision $10 / 10$ while the fellow eye was amblyopic with a central corneal opacity. The boy had been pronounced emmetropic by a school oculist three years before. The fellow eye was removed on account of a penetrating wound one year after the school examination. In each case atropine was used, and retinoscopy revealed myopia of $-2.0 \mathrm{D}$. and $-3.5 \mathrm{D}$. with vision $10 / 10$ and $9 / 10$ respectively. In the first case the myopia had completely disappeared two months later, as verified by retinoscopy. Vision was $10 / 10$ without a lens. In the second case, five months later the myopia was reduced to $-2.75 \mathrm{D}$., and in a further twelve months to $-1.5 \mathrm{D}$. This amount of myopia was still present a year later. As a possible explanation of the persistence of $1.5 \mathrm{D}$. of myopia (after recovery from as much as 3.5D.) it was found that there was a family history of a small amount of myopia. The not very convincing explanation suggested is that a transient paralysis of the peripheral muscle of accommodation ( $d u$ muscle de l'accommodation lointaine) takes place and not a spasm of the proximal muscle of accommodation (accommodateur de près).

Humphrey NeAme.

(4) Bohenberger F. (Leipzig).-A case of double refraction (Ueber einen Fall von zweifacher Refraktion.) Klin. Monatsbl.f. Augenheilk., May, 1926.

(4) Bohenberger records the case of a boy, aged 12 years, who showed double refraction in one eye. The aspect of the eyes suggested high myopia and actually skiascopy revealed about 15D. of myopia. The right eye was amblyopic but the left read $6 / 20$ without any correction and without screwing up his eyes. Concave lenses at first diminished the acuity and then improved it till eventually with $-14 \mathrm{D}$. sph. it reached $6 / 15$. The same acuity was however given with +3.D. sph. Examination under atropine and pilocarpine gave substantially the same readings. J.1. was read without any glass at a distance of $8 \mathrm{~cm}$. The same result was obtained with $+15 \mathrm{D} . \mathrm{sph}$. Careful examination showed that the cause of this double refraction lay in the cornea. Focal illumination revealed several corneal maculae, one of them very delicate and circular in outline lay a little below and outside the apex of the cornea, that is exactly in Aubert's optical zone. By transmitted light it had a dark ring with a clear centre, looking like a button in the centre of the red light of the pupil. Con- 
siderable parallax was noted when the retinal vessels were seen through the centre and outside the central button. The keratoscope gave no further information regarding the nature of the opacity, but the slit-lamp at once gave the required information. When the cornea was examined with the narrow beam, using a series of optical sections, it was seen that the anterior surface of the cornea was slightly flattened but that the posterior surface bulged inwards. There was a cicatricial opacity in the anterior lamellae of the cornea. The use of a contact glass showed that the correction of the myopia was due to the flattening of the anterior surface of the cornea.

\section{T. Harrison Butler.}

(5) Godard, P. J. E - The quadruple stenopaic hole and conditions of ametropia. (Trou quadristénopique et amétropies.) La Clin. Ophtal., September, 1926.

(5) This is quite an interesting and very clearly written article dealing with an elaboration of the ordinary Scheiner experiment. It is doubtful whether the findings obtained by Godard are of real practical value to the clinician, though to the dabbler in subjective experimentation the explanations may be useful. Put as shortly as possible, if an ametrope looks through two or four minute holes in a card at a white disc on the wall or on the table he will see two or four discs and if the card be very slightly moved laterally the two or four spots or.discs will execute lateral movements in the same sense. If the same experiment be tried in an emmetrope only one disc will be seen and no lateral movements thereof on moving the card. The author gives the explanation, which hardly needs to be stated, that in the ametrope the retina cuts the bundles of rays before or behind their focal point and so causes multiplication. With regard to the lateral movements the explanation may be given in the author's words : "It is well known that the ordinary stenopaic opening corrects slight ametropia by cutting out the marginal rays of the cornea. This takes place when the hole is placed exactly opposite the centre of the cornea. But, if it is not placed exactly in the centre it will continue to sharpen the images, but ... this is accompanied by a slight lateral displacement in the retinal projection of the image, so that while the object appears clear it is also seen slightly to one side of the point at which it appears when the hole is exactly central." In these experiments the author has employed a trouser button to provide the four symmetrically placed holes. No one with any sense of humour can fail to visualize the unenviable dilemma of the enthusiastic and excited scientist who has no spares.

ERNEST ThOMSON. 


\section{III. - MISCE LLANEOUS}

(I) Gérard, Georges (Lille).-Collapse of a frontal sinus of the spacious type. (Enfoncement d'un sinus frontal, de la variété des grands sinus.) La Clin. Ophtal., December, 1926.

(1) This article by Gérard is interesting especially from the point of view that our knowledge of the frontal sinuses is comparatively recent, but it is not easy to epitomize on account of the necessarily large amount of quotation involved in the original. The author points out that this knowledge practically dates from 1891 when Mlontaz, of Grenoble, published a little book of eighteen pages containing an accurate account of these sinuses. The reviewer has some reason for supposing that Gérard is correct, for he well remembers about 1892 assisting a friend in an operation on the frontal sinus which was undertaken with considerable hesitation and which resulted in a very prolonged healing. The operation, if the reviewer remembers rightly, was then considered an unusual one. Gérard points out that these sinuses do not appear till about the end of the first year and do not attain their full development until 15 to 20 years. As a rule the anterior wall is much thicker than the posterior but sometimes it is extremely thin. The thickness of the walls is inversely proportional to the size of the cavity, the smaller the cavity the thicker the walls, but, and here is the point, the less is the anterior pole of the cerebral hemisphere protected. The special interest of Gérard's case lies here, for the patient, an elderly man, was apparently saved from severe damage to his brain by the fact that he had large thin-walled sinuses. He had been murderously attacked and had the anterior wall of one sinus pushed in, resulting in tremendous bruising and emphysema of the face, but recovered without damage either to his brain or his visual apparatus. There is a considerable amount of information in this short article which is illustrated with anatomical schemata based on skiagrams, and has a bibliography appended.

\section{ERnest Thomson.}

(2) Kemler, Joseph I. (Baltimore).-Ivory implant after enucleation. Amer. Jl. of Ophthal., January, 1927.

(2) Kemler considers the various substances which have been used as implants after enucleation to be unsatisfactory. They have a strong tendency to be extruded later, while glass has the additional disadvantage of being liable to break, and paraffin to change its location. Organic substances, e.g., fat, fascia lata, and cartilage undergo absorption and in course of time leave only an insignificant trace of their presence. Ivory, however, is very 
satisfactory. It is well tolerated by the surrounding tissues, is not absorbable and cannot break. The prothesis is prepared by taking a one-inch cube of ivory, and rounding off all corners and edges with an electrically driven carborundum wheel until the shape is approximately spherical. A report is given of one case in which ivory was used, with a satisfactory result, though the author does not state how long the case was under observation.

F. A. Williamson-Noble.

\section{BOOK NOTICE}

Handbuch der biologischen Arbeitsmethoden. ByEMIL ABDERHALDEN. Abt. V. Methoden zum Studium der Funktionen der einzelnen Organe des tierischen Organismus. Teil 6 , Heft. 7. Methoden zur Bestimmung des intraokularen Druckes; Methoden zur Untersuchung des intraokularen Flüssigkeitswechsels. By E. SEIDEL. Die Technik der Untersuchung des extramaculären Sehens. By H. LAUBER. Pp. 231 with 57 illustrations. Urban u. Schwarzenberg, Berlin and Vienna, 1927.

The monumental composite work dealing with the practical methods of investigation employed in every known department of biological science is gradually appearing in numerous volumes under the general direction of Professor Abderhalden. The fifth section of the work deals with the chemical, physico-chemical, and biological methods used in the study of the functions of the organs in the animal body, the sixth part of which concerns itself with the eye. This is divided into seven divisions, the sixth of which has now appeared.

The first part of the volume is written by Professor Seidel of Heidelberg, and discusses the methods of measuring the intraocular pressure, and of investigating the intra-ocular fluids. In dealing with the first of these, the various types of tonometers and manometers which have been used from time to time are described and figured, the description covering most of the experimental work which has been done on the intra-ocular pressure. For clinical purposes most attention is given to the tonometer of Schiötz. A similar review follows of the technique employed by the many investigators who have studied the problems of the nature of the aqueous humour, its composition, and the mechanism of its circulation. Seidel has himself done a large amount of work on this subject, a clear account of which is included; he is a strong 